\title{
Subclinical hypothyroidism in the first years of life in patients with Down syndrome
}

\author{
Cristina Claret ${ }^{1,2}$, Albert Goday ${ }^{1-3}$, David Benaiges ${ }^{1,2}$, Juan J. Chillarón ${ }^{1,2}$, Juana A. Flores ${ }^{1,2}$, Elisa Hernandez ${ }^{1,2}$, \\ Josep M. Corretger ${ }^{3}$ and Juan F. Cano ${ }^{1,2}$
}

BACKGROUND: Subclinical hypothyroidism (SH), defined as mild thyroid-stimulating hormone (TSH) elevation with normal free thyroxine (FT4) levels and no symptoms, is common during the first few years of life in Down syndrome (DS) and can be self-limiting. Our objective was to confirm that $\mathrm{SH}$ is usually a transitory disorder and to identify the factors associated with spontaneous remission.

METHODS: We reviewed clinical histories of patients from the Catalan Down Syndrome Foundation (CDSF) with DS and $\mathrm{SH}$ diagnosed before $5 \mathrm{y}$ of age. $\mathrm{SH}$ was defined as TSH $5.5-25 \mu \mathrm{U} / \mathrm{ml}(6 \mathrm{mo}-4 \mathrm{y})$ or $4.13-25 \mu \mathrm{U} / \mathrm{ml}(4-7 \mathrm{y})$, with FT4 $0.89-1.87 \mathrm{ng} / \mathrm{dl}(6 \mathrm{mo}-4 \mathrm{y})$ or $0.96-1.86 \mathrm{ng} / \mathrm{dl}(4-7 \mathrm{y})$.

RESULTS: Fifty-three patients with SH were identified, with an average age of $2.4 \pm 1.1 \mathrm{y}$, median (range) TSH at diagnosis 7.1 (4.2-23.9 $\mathrm{\mu U} / \mathrm{ml})$, and median (range) FT4 1.1 (0.9-1.7 ng/dl). $\mathrm{SH}$ resolved spontaneously in 39 cases (73.6\%), with TSH at the most recent visit (mean age $6.7 \pm 1.4$ y) $3.9(1.8-12.7 \mu \mathrm{U} / \mathrm{ml}$ ). The rate of remission was significantly higher in patients without goiter (94.9 vs. 28.6\%) and in those who were negative for antithyroid antibodies (89.7 vs. 42.9\%).

CONCLUSION: SH in infants and preschool children with DS is usually a transitory disorder, with remission in $>70 \%$ of cases. The absence of goiter and thyroid autoantibodies was associated with a greater rate of spontaneous remission in our study.

$\mathbf{T}$ he prevalence of medical conditions in individuals with Down syndrome (DS) is greater than in the general population, which has negative implications for their quality of life and life expectancy (1). Among these medical problems, thyroid pathology is a primary area of concern. Both hyper- and hypothyroidism occur more often in patients with DS (1-3), the latter disorder occurring six times more frequently than the former $(4,5)$.

In addition to the increased risk of developing autoimmune hypothyroidism with age $(2,6)$, children with DS have a higher chance of displaying a mild, isolated increase in thyroid-stimulating hormone (TSH) in the absence of low free thyroxine (FT4) or overt hypothyroid symptoms $(7,8)$. This phenomenon, of uncertain etiology, can be referred to as subclinical hypothyroidism $(\mathrm{SH})$ and seems usually to be transitory and self-limiting without treatment $(9,10)$. However, there are few systematic studies on $\mathrm{SH}$, and the factors related to its remission are unclear. The possibility that thyroxine replacement may have a beneficial effect on the somatic and psychomotor development of patients with DS and SH has been raised (11). In this context, the results of a randomized, double-blind clinical trial with 196 DS children are important with respect to previous studies. On the basis of the theory that all DS subjects have slight hypothyroidism at birth $(12,13)$, this study evaluated the effect of systematic treatment with levothyroxine initiated in the neonatal period and continued during the first $2 \mathrm{y}$ of life, as compared with that of placebo. Treatment with levothyroxine resulted in a subtle improvement in psychomotor development and somatic growth at $24 \mathrm{mo}$. The study concluded that hormonal treatment should be considered in all newborns with DS to attain optimal development and growth (11). The objective of the current study was to document the natural course of $\mathrm{SH}$ in a population of children with DS younger than $5 \mathrm{y}$ of age and to identify possible factors influencing this course.

\section{RESULTS}

Of a total of 1,903 cases of DS registered with the Catalan Down Syndrome Foundation (CDSF), 149 patients with thyroid dysfunction were identified (a $7.8 \%$ overall prevalence (95\% confidence interval (CI): 6.6-9)) (Figure 1). Of the 149 patients, 12 had hyperthyroidism and 137 had hypothyroidism. We identified 54 patients with TSH elevation aged $<5 \mathrm{y}$, of whom one had overt hypothyroidism with low FT4 and/or total triiodothyronine (TT3) and 53 met our criteria for $\mathrm{SH}$ and were included in the study.

\section{Baseline Characteristics}

Of the 53 cases with DS and SH diagnosed before $5 \mathrm{y}$ of age, 28 were boys and 25 were girls. Follow-up lasted $54 \pm 19$ mo. Median (range) age at diagnosis was $2.2(0.3-4.9) \mathrm{y}$, mean age was $2.4 \pm 1.1 \mathrm{y}$. Median age at the most recent visit was 6.6 (3.511.4) y, mean age was $6.7 \pm 1.4 \mathrm{y}$. Thirteen patients had a family history of thyroid pathology (24.5\% (95\% CI: 12.9-36.1)), 


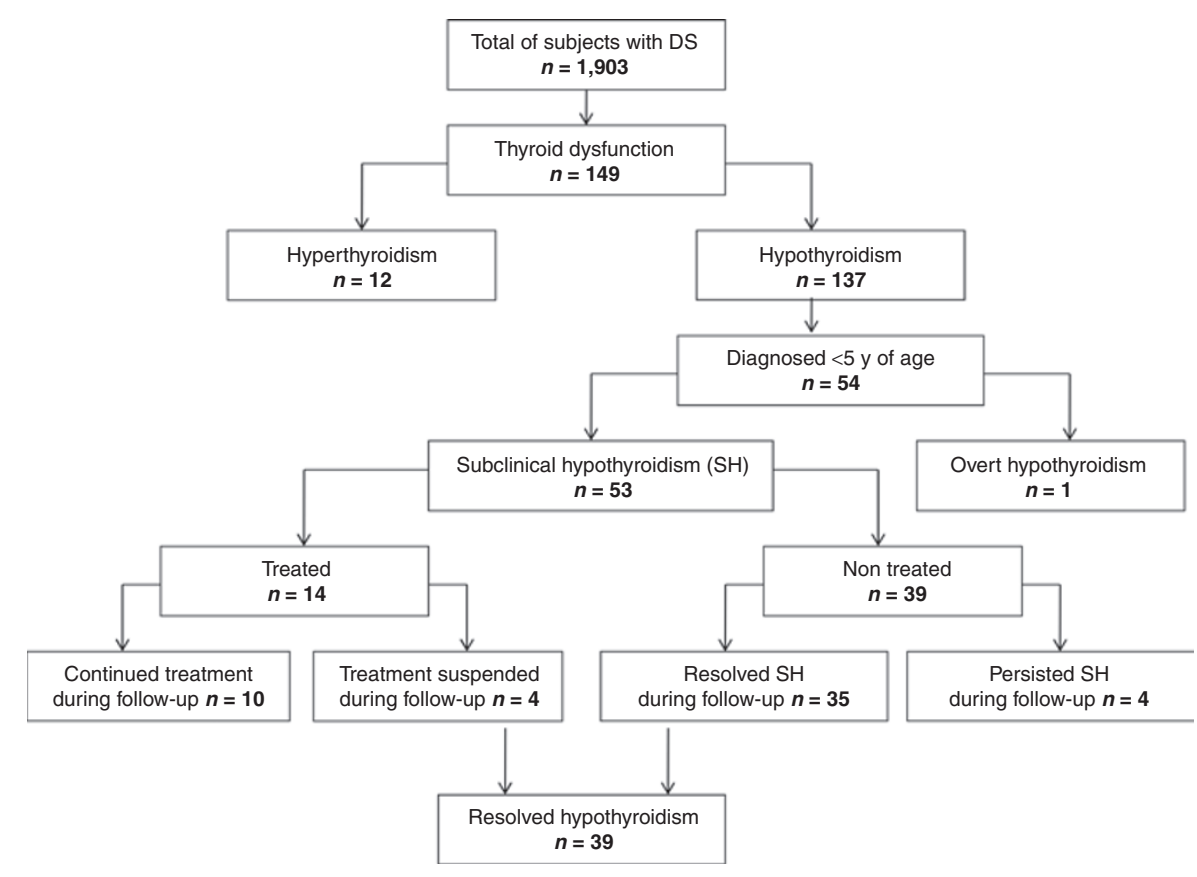

Figure 1. Flow diagram of all patients with Down syndrome (DS) and hypothyroidism from the Catalan Down Syndrome Foundation database. Of the 53 patients included in the study, subclinical hypothyroidism (SH) resolved in 39 cases.

in most cases, multinodular goiter and hypothyroidism, with predominance of the maternal line. Analysis of karyotype was available in all cases, which confirmed trisomy of chromosome 21 as the most common genetic alteration $(n=47,88.7 \%(95 \%$ CI: 80.1-97.2)), followed less frequently by mosaicism $(n=4$, 7.5\% (95\% CI: $0.4-14.7 \%))$ and translocation 14/21 $(n=2$, $3.8 \%$ (95\% CI: $-1.3-8.9 \%)$ ). Simultaneous medical conditions were highly prevalent, especially congenital cardiac malformations, which affected 23 cases (43.4\% (95\% CI: 30.1-56.7)).

\section{Signs and Symptoms}

A total of 19 patients (35.8\% (95\% CI: 22.9-48.8)) showed some signs or symptoms suggestive of hypothyroidism. The most frequently described symptoms were constipation, rough/dry/ cold skin, and overweight, with four cases each. The average score on the Billewicz scale was $-3.9 \pm 11.9$ (nonspecific), and none of the patients scored above +29 . There were no differences in TSH mean/median values between patients with and without symptoms (mean $8.2 \pm 2.9 \mu \mathrm{U} / \mathrm{ml} /$ median (range) 7.3 $(4.8-23.9 \mu \mathrm{U} / \mathrm{ml})$ vs. mean $8 \pm 2.8 /$ median (range) 7.1 (4.2$14.5 \mu \mathrm{U} / \mathrm{ml}$ ), respectively, $P=0.5$ ). Examination of the neck by clinical exam or ultrasonography revealed the presence of goiter in 12 cases (22.6\% (95\% CI: 11.4-33.9)).

\section{Anthropometric Data}

The average weight percentile for the Spanish population with DS was $55 \pm 14.2$ at the time of diagnosis, and the average length/ height percentile was $45.7 \pm 16.6$. Children's BMI at diagnosis was $16.5 \pm 1.3$, with an average BMI percentile of $59.3 \pm 21.2$ for the general population. The percentage of overweight patients at the time of diagnosis was $21.9 \%$ (95\% CI: 9.1-37), and obesity was found in $11.4 \%$ of cases (95\% CI: 0.6-21.4).
Comparison of weight and length/height percentiles between the treated and the untreated cases is shown in Table 1. There were no significant differences between the two groups in terms of initial weight and length/height percentiles or when measured at 1 and $2 \mathrm{y}$.

\section{Laboratory Data}

None of the subjects were on medication that may have affected the TSH determinations. Mean TSH at diagnosis was $8 \pm 2.8 \mu \mathrm{U} / \mathrm{ml}$, median (range) $7.1(4.2-23.9) \mu \mathrm{U} / \mathrm{ml}$, and mean FT4 was $1.2 \pm 0.48$, median (range) $1.1(0.9-1.7) \mu \mathrm{U} /$ $\mathrm{ml}$. In our cohort, SH resolved in 39 of the 53 cases $(73.6 \%$ (95\% CI: 61.7-85.4)), spontaneously in 35 cases, and after levothyroxine was withdrawn in four patients (Figure 1). The average interval between diagnosis of thyroid dysfunction and documentation of remission was $13.2 \pm 11.1 \mathrm{mo}$, with most cases resolving between 4 and 5 y of age (Figure 2). In this group of patients with resolved $\mathrm{SH}$, the mean age at the last recorded visit was $6.8 \pm 1.4 \mathrm{y}$, median (range) 6.7 (3.5-11.4), whereas mean TSH was $3.6 \pm 1.9 \mu \mathrm{U} / \mathrm{ml}$, median (range) $3.2(1.8-3.8) \mu \mathrm{U} / \mathrm{ml}$. No patient progressed to overt hypothyroidism (low levels of TT3 and/or FT4) during the period of observation.

Positive antithyroperoxidase and antithyroglobulin antibodies were detected in 12 cases (22.6\% (95\% CI: 11.4-33.9\%)), at a median (range) age of $2.8(1.6-4.9) \mathrm{y}$.

The rate of remission was significantly higher in patients without goiter ( 94.9 vs. $28.6 \%$ ), and in patients who were negative for antithyroid antibodies (89.7 vs. $42.9 \%$ ). Other factors analyzed but not found to be associated with remission included age, sex, family history of thyroid disease, symptoms, and average TSH level at the time of diagnosis (Table 2). In the 


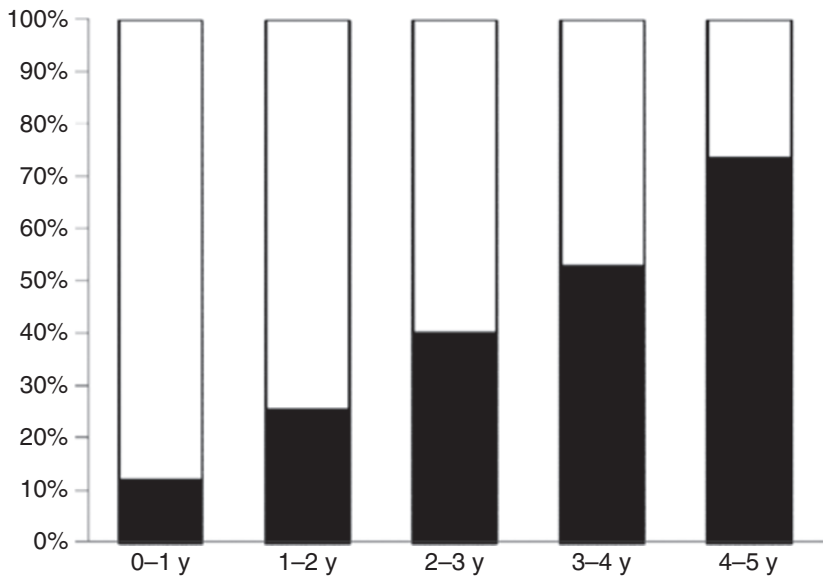

Figure 2. Rate of remission (\%) of subclinical hypothyroidism depending on age range: white bars represent unresolved cases; black bars represent resolved cases.

Table 1. Comparison of biochemical and anthropometric measures at baseline and during follow-up in untreated and treated patients

\begin{tabular}{|c|c|c|c|}
\hline & $\begin{array}{l}\text { Untreated } \\
\text { cases }\end{array}$ & $\begin{array}{l}\text { Treated } \\
\text { cases }\end{array}$ & $P$ \\
\hline$n(\%)$ & $39(73.6 \%)$ & $14(26.4 \%)$ & - \\
\hline Resolved cases, $n(\%)$ & $35(89.7 \%)$ & $4(28.6 \%)$ & $<0.05$ \\
\hline $\begin{array}{l}\text { Symptoms/signs of } \\
\text { hypothyroidism, } n(\%)\end{array}$ & $13(33.3 \%)$ & $6(42.8 \%)$ & 0.29 \\
\hline $\begin{array}{l}\text { Weight percentile at } \\
\text { diagnosis } \pm S D\end{array}$ & $55.8 \pm 14.4$ & $50 \pm 13.9$ & 0.39 \\
\hline Weight percentile at $1 \mathrm{y} \pm \mathrm{SD}$ & $59.1 \pm 16$ & $59.6 \pm 17.1$ & 0.87 \\
\hline Weight percentile at $2 \mathrm{y} \pm$ SD & $62.5 \pm 15.5$ & $59.9 \pm 17.5$ & 0.28 \\
\hline $\begin{array}{l}\text { Length/height percentile at } \\
\text { diagnosis } \pm \text { SD }\end{array}$ & $46.7 \pm 16.3$ & $42.7 \pm 18.4$ & 0.52 \\
\hline $\begin{array}{l}\text { Length/height percentile at } \\
1 \mathrm{y} \pm S D\end{array}$ & $50.8 \pm 17.5$ & $47 \pm 22.4$ & 0.60 \\
\hline $\begin{array}{l}\text { Length/height percentile at } \\
2 y \pm S D\end{array}$ & $50.9 \pm 20.3$ & $50.6 \pm 21$ & 0.57 \\
\hline $\begin{array}{l}\text { Median TSH level at diagnosis } \\
\text { (range) }(\mu \mathrm{U} / \mathrm{ml})\end{array}$ & $6.9(4.2-9.6)$ & $10.7(9.8-23.9)$ & 0.46 \\
\hline $\begin{array}{l}\text { Median FT4 level at diagnosis } \\
\text { (range) (ng/dl) }\end{array}$ & $1.1(1-1.7)$ & $1(0.9-1.5)$ & 0.62 \\
\hline Goiter, $n(\%)$ & $5(12.8 \%)$ & $7(50 \%)$ & $<0.05$ \\
\hline Antibodies TPO/TGB + n (\%) & $4(10.2 \%)$ & $8(57.1 \%)$ & $<0.05$ \\
\hline
\end{tabular}

$\mathrm{FT}$, free thyroxine; $\mathrm{TGB}$, thyroglobulin; TPO, thyroperoxidase; $\mathrm{TSH}$, thyroid-stimulating hormone.

multivariate logistic regression analysis, the presence of goiter was associated, independently and significantly, with nonresolution or persistence of $\mathrm{SH}(P<0.05$, odds ratio $=13.7(4.5-$ 35.6)). The positivity of the antibodies did not reach statistical significance $(P=0.06$, odds ratio $=10.9(0.84-40.6))$.

\section{Treatment With Levothyroxine}

Overall, 14 patients (26.4\%) received treatment with levothyroxine. In most of the cases, the indication for treatment was a TSH value higher than $10 \mu \mathrm{U} / \mathrm{ml}$ (in one case, it was cardiac surgery
Table 2. Factors associated with remission of subclinical hypothyroidism

\begin{tabular}{|c|c|c|c|}
\hline & Remission & Persistence & $P$ \\
\hline$n(\%)$ & $39(73.6 \%)$ & $14(26.4 \%)$ & - \\
\hline $\begin{array}{l}\text { Median age at diagnosis (range) } \\
\text { (years) }\end{array}$ & $2.2(0.3-4.9)$ & $2.2(1.1-4.7)$ & 0.95 \\
\hline $\begin{array}{l}\text { Median age at the last recorded } \\
\text { visit (range) (years) }\end{array}$ & $6.7(3.5-11.4)$ & $6.5(3.7-10.9)$ & 0.67 \\
\hline Sex (\% girls) & $47.4 \%$ & $50 \%$ & 0.29 \\
\hline $\begin{array}{l}\text { Family history of thyroid disease, } \\
n(\%)\end{array}$ & $8(20.5 \%)$ & $5(35.7 \%)$ & 0.33 \\
\hline $\begin{array}{l}\text { Symptoms/signs at diagnosis, } \\
n(\%)\end{array}$ & $11(28.2 \%)$ & $8(28.6 \%)$ & 0.72 \\
\hline $\begin{array}{l}\text { Median TSH level at diagnosis } \\
\text { (range) }(\mu \mathrm{U} / \mathrm{ml})\end{array}$ & $6.9(4.2-9)$ & $9.1(5.4-23.9)$ & 0.13 \\
\hline $\begin{array}{l}\text { Median FT4 level at diagnosis } \\
\text { (range) (ng/dl) }\end{array}$ & $1.1(1-1.7)$ & $1(0.9-1.5)$ & 0.58 \\
\hline Absence of goiter, $n(\%)$ & $37(94.9 \%)$ & $4(28.6 \%)$ & $<0.05$ \\
\hline $\begin{array}{l}\text { Negative for antibodies to } \\
\text { TPO/TGB, } n(\%)\end{array}$ & $35(89.7 \%)$ & $6(42.9 \%)$ & $<0.05$ \\
\hline
\end{tabular}

$\mathrm{FT} 4$, free thyroxine; TGB, thyroglobulin; TPO, thyroperoxidase; TSH, thyroid-stimulating hormone.

due to a congenital cardiac malformation). Mean age at the start of treatment was $4.4 \pm 3 \mathrm{y}$, and mean TSH was $10.9 \pm 1.3 \mu \mathrm{U} /$ $\mathrm{ml}$. Average initial dose of levothyroxine per kilogram was $1 \pm$ $0.4 \mu \mathrm{g} / \mathrm{kg} / \mathrm{d}(1.1 \pm 0.3 \mu \mathrm{g} / \mathrm{kg}$ in boys and $0.9 \pm 0.5 \mu \mathrm{g} / \mathrm{kg}$ in girls $)$.

\section{DISCUSSION}

We have observed in the current study that hypothyroidism in the first years of life in patients with DS tends to present as a slight and subclinical alteration. Distribution of $\mathrm{SH}$ during this initial stage is balanced between both sexes, in contrast to the usual female predominance in hypothyroidism (14-17), and diagnosis is made essentially by routine lab screening. Most of the cases resolved without treatment, whereas persistence or progression toward overt hypothyroidism appeared to be linked to the presence of autoimmune factors.

The cause of this disorder is not clear. Karlsson et al. indicate in their study that autoimmunity does not seem to play an essential role in this disorder, because it appears much later on, during school-age years (14). The study by Van Trotsenburg et al. suggests that virtually all individuals with DS have a congenital alteration in the regulation of the thyroid gland itself, which would be in direct relation to the trisomy condition of chromosome 21 (11). For cases of early and mild $\mathrm{SH}$, the general trend is a follow-up testing without initial therapeutic intervention, given the frequent remission of the disorder (18). In fact, a longitudinal study by Gibson et al. showed that only one of 20 cases of children with DS and isolated increase in TSH developed clinical hypothyroidism in a second hormone analysis conducted 4-6 y later. In addition, TSH values returned to normal levels within a short period of time (9). 
The presence of goiter or antibodies suggests the development of an autoimmune thyroiditis, the nature of which is thus different from the hypothyroidism observed in the majority of these children (14). In our study, the presence of goiter was found to be an independent factor significantly associated with persistence of SH. The average urinary iodine in Catalonia, the region in which the study was carried out, is within the levels recommended by the World Health Organization (19). The positivity of antithyroidal antibodies seems to be also an associated factor, although it did not reach statistical significance in our multivariate analysis. This could be explained because this variable was registered as a categorical and not as a continuous variable, and also because the number of cases was relatively low.

It has been suggested that $\mathrm{SH}$ may contribute to delayed growth and/or impaired intellectual development in DS, thereby aggravating the mental disability that is inherent to the underlying syndrome. However, results of studies on this aspect are uneven. Papendieck et al. were not able to demonstrate that patients with DS and increased TSH values had abnormal growth, nor that it could improve under treatment with thyroid hormone (1). Another study also did not find any differences when comparing growth and intellectual development of children with compensated hypothyroidism (subclinical) with a control group with normal thyroid function (10). On the contrary, in a longitudinal study by Karlsson et al., children with hypothyroidism had, in the year before starting treatment with levothyroxine, a lower growth rate as compared with children with normal thyroid levels and DS of the same age and sex (controls), and this rate of growth improved during the first year of treatment (14). The results of Van Trotsenburg and colleagues' trial encouraged early treatment starting in the neonatal stage, considering that all individuals with DS have mild hypothyroidism at birth (11). In this study, there was improvement in development at $2 \mathrm{y}$ in the group of treated newborns as compared with the placebo group, but these differences were subtle and probably have scant clinical relevance, especially with respect to somatic growth. Moreover, these patients were assessed at a very young age, $24 \mathrm{mo}$, and this cohort would need to be older before any significant differences in cognition could be verified.

In our series, hormonal treatment in subclinical stages, at least during $2 \mathrm{y}$, does not seem to have clinical repercussions on the length/height of these children, although it must be taken into account that assessment of change in growth percentile is not a good marker of potential therapeutic efficacy for DS patients with mild elevations in TSH, and the analysis was limited to a 2-y period. Therefore, the evidence from our study is not strong enough to draw conclusions about this issue. The main limitations of the current study include the retrospective observational design, the absence of a control group, the small sample size, and the lack of information about the psychomotor development of the studied patients. We attempted to apply a systematized scoring scale of signs and symptoms to patients (20); however, this method of correlation turned out to be of little use in practice because the average score on the scale was negative, and therefore, indeterminate. This means that clinical symptoms do not have very much value for diagnosis, even in cases with very elevated TSH values and T4 below normal limits (21). In fact, our only patient with decreased T4 did not present any suggestive symptoms of hypothyroidism. In addition, symptoms of hypothyroidism are very nonspecific because they overlap with those inherent to DS (22). For this reason, regardless of the high rate of spontaneous resolution and the uncertainty about real clinical impact, we consider that annual capillary TSH screening is a reasonable and feasible practice in these children (23).

In summary, early childhood hypothyroidism in patients with DS manifests itself as a subclinical and, in most of cases, transitory disorder. Factors associated with spontaneous remission of SH are the absence of goiter and antithyroid antibodies. We finally suggest the following practical approach to the management of a newborn with DS and hypothyroidism:

1. If TSH is above the normal range for age but $<10 \mu \mathrm{U} / \mathrm{ml}$, consider treatment if goiter and/or antithyroid antibodies are present. If they are absent, an initial expectant attitude can be adopted.

2. If TSH is $>10 \mu \mathrm{U} / \mathrm{ml}$, it is reasonable for the clinician to treat the child initially but to re-evaluate off treatment at a later date, to see if the SH has resolved.

3. If FT4 and/or TT3 are below the normal range for age and TSH is elevated, irrespective of symptomatology, treatment should be started.

\section{METHODS}

\section{Patients}

Data were collected through a review of the clinical histories of patients with DS from the CDSF, recorded between 1993 and 2008. The CDSF, established in 1984, is a nonprofit organization whose purpose is to promote the full development of persons with DS in Catalonia. It provides support to patients from prenatal diagnosis to adulthood but does not include a complete demographic registry of all patients with DS. In addition to the capillary blood test for TSH that is applied universally to all newborn infants, the foundation's health program includes a systematic screening for thyroid diseases with annual venous TSH determination from $1 \mathrm{y}$ of age. If any alteration in thyroid function screening is detected by the pediatrician, the patient is referred to the endocrinologist for evaluation. Similarly, the patient is evaluated by the endocrinologist when thyroid dysfunction is discovered by chance in a laboratory test performed for another purpose. Patients with clinical suspicion of hypothyroidism are also tested at any time.

$\mathrm{SH}$ was defined as TSH between $5.5-25 \mu \mathrm{U} / \mathrm{ml}(6 \mathrm{mo}-4$ y) or $4.13-25 \mu \mathrm{U} / \mathrm{ml}(4-7 \mathrm{y})$, with FT4 and/or TT3 within the normal range for age (FT4: $0.89-1.87 \mathrm{ng} / \mathrm{dl}(6 \mathrm{mo}-4 \mathrm{y})$ and $0.96-1.86 \mathrm{ng} / \mathrm{dl}(4-7 \mathrm{y})$ ) (TT3: $0.75-2.05 \mathrm{ng} / \mathrm{dl}(6 \mathrm{mo}-4 \mathrm{y})$ and $1-1.78 \mathrm{ng} / \mathrm{dl}(4-7 \mathrm{y}))$. Overt hypothyroidism was defined as TSH elevation with subnormal FT4 and/or TT3. The CDSF database was analyzed, and all patients with $\mathrm{SH}$ were identified. All patients included in the study were younger than $5 \mathrm{y}$ of age at the time of diagnosis and had been evaluated by the same endocrinologist. Patients had been followed up every 6-12 mo, or more frequently when indicated. The study was approved by the clinical research ethics committee of the CDSF.

\section{Clinical Data}

Age at diagnosis of hypothyroidism, sex, presence of family history of thyroid disease, type of genetic alterations associated with DS, and associated medical conditions were included. Signs and symptoms of hypothyroidism at diagnosis and during follow-up were systematically collected, using the Billewicz scoring scale (20). This scale adds or subtracts points, depending on the presence or absence of various 
signs and symptoms. Normally individuals with hypothyroidism score above +29 , whereas individuals with normal thyroid hormone levels score below -4 . Scores between -4 and +29 are considered inconclusive. The presence of goiter had been analyzed by clinical examination or, in a few patients, by performing a thyroid ultrasonography at diagnosis. Goiter was defined clinically when the diameter of thyroid lobes was longer than the size of the terminal phalanx of the child's thumb. Ultrasonography was performed in the most recent years using an Aloka 630 ultrasound machine with a $7.5-\mathrm{MHz}$ transducer (Aloka, Madrid, Spain). Thyroid volume was calculated as the sum of the volumes of both lobes. Cutoffs for thyroid volumes were based on local data. Goiter was defined by ultrasonography as a thyroid volume above $1.5(0-1 \mathrm{y}), 2.5$ (1-3 y), 4 (3-5 y), and $4.5 \mathrm{ml}(5-6 \mathrm{y})$.

\section{Anthropometric Measurements}

Weight and length/height were recorded by direct measurement in light clothing and without footwear, and compared with percentiles corresponding to the Spanish population with DS (24). Children's BMI was calculated for patients older than $2 y$ of age. These parameters were collected annually during the follow-up of these patients. In our study, we collected weight and length/height percentiles at diagnosis and during the first $2 \mathrm{y}$ and we compared them between the treated and the untreated groups.

\section{Laboratory Data}

TSH, FT4, and TT3 were measured using the IBA/Cis Bio International (Gif-sur-Yvette, France) radioimmunoassay (coefficients of betweenassay variation 5-10\%). Antithyroperoxidase and antithyroglobulin antibodies were measured with the corresponding radioimmunoassay kit (Roche, Meylan, France). The positivity or negativity of antithyroperoxidase antibodies and/or antithyroglobulin antibodies was registered as a categorical variable.

\section{Evolution and Treatment Dosage}

Remission of SH was defined as the return of TSH values to normal levels without the need to begin hormonal treatment or after such treatment has been suspended for at least 12 mo. Time elapsed until remission and associated factors were determined. The criteria that the endocrinologist had used for starting hormone replacement treatment was a sustained TSH value $\geq 10 \mu \mathrm{U} / \mathrm{ml}$, and/or a drop in peripheral hormones T3 and/or T4, or if cardiac surgery was indicated, given the importance of attaining strictly normal thyroid function in this situation. For cases in treatment with levothyroxine, the average initial and follow-up doses, as well as the annual changes in these doses, were recorded by age and sex.

\section{Statistical Analysis}

Differences between groups were analyzed using the $\chi^{2}$ test for categorized variables, the independent sample $t$-test for continuous variables, and the Mann-Whitney $U$ test for TSH, FT4, and TT3 because these variables were not normally distributed. We applied a multiple logistic regression model to evaluate the factors associated with the persistence of hypothyrodism (dependent variable), in which we included those independent variables that had a $P$ value $<0.05$ in the univariate analysis. We considered the level of significance as $P<0.05$. Analyses were performed using the Statistical Package for Social Sciences, version 17.0 (SPSS, Chicago, IL).

\section{ACKNOWLEDGMENTS}

We thank Reyes Alcoverro, secretary of the Medical Center of CDSF, for the facilities for the collection of clinical data for our study.

\section{STATEMENT OF FINANCIAL SUPPORT}

No financial assistance was received to support this study.

Disclosure: The authors declare no conflict of interest.

\section{REFERENCES}

1. Gruñeiro de Papendieck L, Chiesa A, Bastida MG, Alonso G, Finkielstain G, Heinrich JJ. Thyroid dysfunction and high thyroid stimulating hormone levels in children with Down's syndrome. J Pediatr Endocrinol Metab 2002;15:1543-8.

2. Pueschel SM, Jackson IM, Giesswein P, Dean MK, Pezzullo JC. Thyroid function in Down syndrome. Res Dev Disabil 1991;12:287-96.

3. Goday-Arno A, Cerda-Esteva M, Flores-Le-Roux JA, Chillaron-Jordan JJ, Corretger JM, Cano-Pérez JF. Hyperthyroidism in a population with Down syndrome. Clin Endocrinol (Oxf) 2009;71:110-4.

4. Prasher V. Prevalence of thyroid dysfunction and autoimmunity in adults with Down syndrome. Downs Syndr Res Pract 1994;2:67-70.

5. Kinnell HG, Gibbs N, Teale JD, Smith J. Thyroid dysfunction in institutionalised Down's syndrome adults. Psychol Med 1987;17:387-92.

6. Rubello D, Pozzan GB, Casara D, et al. Natural course of subclinical hypothyroidism in Down's syndrome: prospective study results and therapeutic considerations. J Endocrinol Invest 1995;18:35-40.

7. Cutler AT, Benezra-Obeiter R, Brink SJ. Thyroid function in young children with Down syndrome. Am J Dis Child 1986;140:479-83.

8. Sharav T, Collins RM Jr, Baab PJ. Growth studies in infants and children with Down's syndrome and elevated levels of thyrotropin. Am J Dis Child 1988;142:1302-6.

9. Gibson PA, Newton RW, Selby K, Price DA, Leyland K, Addison GM. Longitudinal study of thyroid function in Down's syndrome in the first two decades. Arch Dis Child 2005;90:574-8.

10. Selikowitz M. A five-year longitudinal study of thyroid function in children with Down syndrome. Dev Med Child Neurol 1993;35:396-401.

11. van Trotsenburg AS, Vulsma T, van Rozenburg-Marres SL, et al. The effect of thyroxine treatment started in the neonatal period on development and growth of two-year-old Down syndrome children: a randomized clinical trial. J Clin Endocrinol Metab 2005;90:3304-11.

12. van Trotsenburg AS, Kempers MJ, Endert E, Tijssen JG, de Vijlder JJ, Vulsma T. Trisomy 21 causes persistent congenital hypothyroidism presumably of thyroidal origin. Thyroid 2006;16:671-80.

13. van Trotsenburg AS, Vulsma T, van Santen HM, Cheung W, de Vijlder JJ. Lower neonatal screening thyroxine concentrations in down syndrome newborns. J Clin Endocrinol Metab 2003;88:1512-5.

14. Karlsson B, Gustafsson J, Hedov G, Ivarsson SA, Annerén G. Thyroid dysfunction in Down's syndrome: relation to age and thyroid autoimmunity. Arch Dis Child 1998;79:242-5.

15. Zori RT, Schatz DA, Ostrer H, Williams CA, Spillar R, Riley WJ. Relationship of autoimmunity to thyroid dysfunction in children and adults with Down syndrome. Am J Med Genet Suppl 1990;7:238-41.

16. Popova G, Paterson WF, Brown A, Donaldson MD. Hashimoto's thyroiditis in Down's syndrome: clinical presentation and evolution. Horm Res 2008;70:278-84.

17. Jiménez-López V, Arias A, Arata-Bellabarba G, Vivas E, Delgado MC, Paoli M. Concentration of thyrotropic hormone and free thyroxin in children with Down's syndrome. Invest Clin 2001;42:123-30.

18. Tüysüz B, Beker DB. Thyroid dysfunction in children with Down's syndrome. Acta Paediatr 2001;90:1389-93.

19. Vila L, Castell C, Wengrowicz S, de Lara N, Casamitjana R. [Urinary iodide assessment of the adult population in Catalonia]. Med Clin (Barc) 2006;127:730-3.

20. Billewicz WZ, Chapman RS, Crooks J, et al. Statistical methods applied to the diagnosis of hypothyroidism. Q J Med 1969;38:255-66.

21. Noble SE, Leyland K, Findlay CA, et al. School based screening for hypothyroidism in Down's syndrome by dried blood spot TSH measurement. Arch Dis Child 2000;82:27-31.

22. Dinani S, Carpenter S. Down's syndrome and thyroid disorder. J Ment Defic Res 1990;34 (Pt 2):187-93.

23 McGowan S, Jones J, Brown A, et al. Capillary TSH screening programme for Down's syndrome in Scotland, 1997-2009. Arch Dis Child 2011;96:1113-7.

24. Pastor X, Quintó L, Corretger JM, Gassió R, Hernández M, Serés A. [Updated growth charts of Spanish children with Down syndrome]. Revista médica internacional sobre el síndrome de Down 2004;8: $34-46$. 